\title{
Employing Computer Optimization in Powerplant Design
}

\section{Robert McMasters P.E., Virginia Military Institute}

Robert L. McMasters was born in Ferndale, Michigan, in 1956. He graduated from the U.S. Naval Academy, Annapolis Md, in June 1978 and completed Naval Nuclear Propulsion Training in August 1979. He subsequently served as a division officer on the USS Will Rogers (SSBN 659) until 1982. Following a 2 year tour as an instructor at the S1W prototype of the Nautilus, the worlds first nuclear powered ship, he resigned his commission as a Naval Officer and began working as a design engineer at K.I. Sawyer Air Force Base near Marquette Michigan and later at Michigan State University in East Lansing Michigan. He completed the Ph.D. at Michigan State University in 1997 and continued to serve there as a Visiting Assistant Professor until 2004 when he accepted an Associate Professor position at the Virginia Military Institute (VMI) in Lexington, Va. He currently serves as a Professor of Mechanical Engineering at VMI. 


\section{Employing Computer Optimization in Powerplant Design}




\begin{abstract}
As an undergraduate senior elective course, powerplant design is not commonly offered in most mechanical engineering curricula. Many aspects of poweplant design may be included in an advanced undergraduate thermodynamics course. Traditionally, assigned exercises involving powerplants have involved laborious interpolation from thermodynamic tables in order to obtain steam and condensate properties. With the advent of computerized thermodynamic functions, more advanced exercises can be formulated, with the time-intensive aspect of table interpolation no longer necessary.
\end{abstract}

This paper presents a portfolio of exercises which have been incorporated into a powerplant design course involving plant efficiency optimization through the use of pressure and temperature design selections at various strategic points in the plant. Additionally, components such as cooling towers involving psychrometric calculations are handled using computerized property software and incorporated into the powerplant design course. The models for these problems are generated from scratch by the students with no special software beyond the commonly-used thermodynamic property packages that are available as part of Engineering Equation Solver (EES), Microsoft Excel, MATLAB or Mathcad. Using these tools, students can be exposed to the effects of powerplant component design features, such as re-heater pressure and feedwater heater pressure on overall plant performance. Additionally, students can explore the effects of outdoor relative humidity on the performance of cooling towers for various design parameters they might select. Generating plots from the results of their designs gives students insight into the sensitivity of the performance of various components to the design parameters they have been asked to vary. They can also observe the effects of the performance of individual components on the overall performance of the plant. By assembling components over the duration of the semester, the interrelationship of the segments of the plant can be seen. For example, an integrated plant exercise includes the effect of outdoor relative humidity on overall plant performance, taking into account the interrelation between outdoor humidity, cooling water temperature, condenser vacuum and turbine output.

Fundamental computer-based exercises related to nuclear power generation are also included, allowing students to observe the influence of moderator atomic mass on the thermalization rate of neutrons, and the time-response of reactor thermal power to primary coolant loop sizing. Each of these exercises is generated by employing foundational principles using the generic software packages mentioned previously.

\title{
Introduction
}

Although Powerplant Design is not a commonly-offered course, it is important for universities to produce mechanical engineers who are well trained to work in that field, particularly with a potential renaissance in nuclear power beginning to take shape. The demise of nuclear power over the last 35 years has left many operating plants with a greying staff of engineers, many of whom will retire within the next decade. Some aspects of poweplant design are taught in thermodynamics courses, particularly in curricula which require a two-course sequence in thermodynamics. With the arrival of computerized thermodynamic functions, laborious interpolation from thermodynamic tables can be reduced or eliminated, allowing more advanced 
exercises to be formulated. Computerized thermodynamic properties have been introduced for classroom instruction and for homework assignments at many points over the last decade. One of the first to do this was McClain [1] who developed ideal gas thermodynamic properties using MathCad for dealing with gas turbine problems and other cases where ideal gasses are used. This work was expanded by McClain [2] in establishing exercises for students using the MathCad thermodynamic property functions. This work was continued by Maixner et al [3], specifically for analyzing gas turbine problems. Thermodynamic functions have also been programmed in Microsoft Excel for determining thermodynamic properties specifically for a combined powerplant cycle analysis by Maixner [4]. Additionally a graphic depiction of thermodynamic processes is provided by Maixner [5]. Both of these references used techniques taught in courses offered commercially by SpreadsheetWorld [6]. Later, Microsoft Excel was used by Taylor et al [7] for determining thermodynamic properties used in typical thermodynamics courses. The Excel functions employed in these courses were generated by Holmgren [8] which provides a pre-programmed file that can be downloaded by students. Other work produced by Dechant et al [9] also has used computer-generated thermodynamic property information, in this particular case generated by Engineering Equation Solver (EES).

The current research presented here provides a portfolio of exercises which have been incorporated into a powerplant design course involving plant efficiency optimization. The textbook used in the course is by El-Wakil [10] but the exercises used in the course are not taken from this book. Instead, they have been devised by the instructor and placed on a web page for students to access. Components such as cooling towers are addressed in which students develop their own computerized properties for air and water mixtures. The concepts for developing these properties come from Cengel and Boles [11] but can be found in most thermodynamics textbooks. Using these tools, students can be exposed to the effects of outdoor relative humidity on the performance of cooling towers for various design parameters they might select. The computerized nature of the results allows students to easily generate plots from the results of their designs, allowing insight into the sensitivity of the performance of various components as functions of the design parameters they have been asked to vary. Additionally, an integrated plant exercise allows students to observe the effect of outdoor relative humidity on overall plant performance, taking into account the interrelation between outdoor humidity, cooling water temperature, condenser vacuum and turbine output.

Extending the concept of computer optimization to aspects of nuclear energy generation, computer-based exercises related to nuclear power are also included as part of this work. These exercises allow students to observe the influence of moderator atomic mass on the thermalization rate of neutrons. The time response of reactor thermal power to primary coolant loop sizing is examined in another exercise. Each of these exercises is generated using foundational principles through the use of generic software packages chosen by the students, thus giving them more ownership over the process as opposed to viewing the work purely a classroom exercise prescribed by the instructor.

\section{Classroom Instruction}

For students enrolled in the Powerplant Design course, there is very little explanation of theory required for most of the thermodynamic problems, since two semesters of Thermodynamics is a 
prerequisite for the course. Therefore, the majority of the course instruction consists of exposing the students to new application for the thermodynamic principles they are already familiar with. Some review is necessary, since this course is normally offered in the fall semester and, in some cases, the students have not taken a thermodynamics course since the previous fall semester. Therefore, some class time is devoted to the review of thermodynamic fundamentals such as enthalpy, mass flow rate, power, and the recovery of thermodynamic properties from computerized resources. However, most of the classroom instruction time is devoted to working examples that are similar to the homework problems. A computer workstation in the classroom, connected to a projector, is used in order to work the examples in class. Side-points of interest are introduced, such as an order-of-magnitude analysis of powerplant costs, as given in Equation (1) below, in order to impart context to the homework and example problems. A review of Psychrometrics is normally required, as given in Equations (2-7)

Some theoretical background is required for topics in the nuclear field, since most students in the Mechanical Engineering major have not been introduced to these concepts before. Although most students have been exposed to conservation of momentum and kinetic energy in their Physics courses, as well as in Dynamics, the application of these concepts to particle collision must be derived in class using Equations (8-10). Also, considerable amount of background information must be developed for reactor dynamics, including the response of neutron flux level to the introduction of reactivity. Equation (11) is derived in class for this purpose, specifically addressing the reactivity associated with reactor temperature changes and the resulting effect on neutron flux level.

\section{Homework Problem 1: Optimizing Reheat Pressures}

Boiler reheat is a concept that is often introduced in a second course on thermodynamics. In such cases, the reheat stages are assumed to be constant-pressure processes, but the pressures at which each stage operates are given. With the use of computerized thermodynamic property functions, such as Reference [8], EES, or another function-based program, there is very little additional effort involved in optimizing the reheat pressure values in order to maximize plant efficiency. Moreover, students are required to provide an initial pressure value for each stage of reheat in order to facilitate the optimization process. In doing so, they notice the plant efficiency which resulted from their initial value prior to optimization and can compare that with the efficiency value they obtain after the optimization is complete. Figure 1 shows a schematic diagram of a double-reheat boiler having three turbines.

Once the students establish initial values for the reheat pressures, they can use plant efficiency as an optimizing criterion and maximize this value by allowing the computer program to adjust the reheat pressures. This is done in the Excel-based programs by the use of the "Solver" feature which, although a standard part of Excel, normally has to be initiated as an "add-in" via the "Options" selection on Excel. For optimization with more than one independent variable, Solver must be used in lieu of Goal Seek, since the latter can only handle one independent variable. Moreover, Goal Seek is only capable of forcing the dependent variable to be equivalent to a selected value; it is not capable of minimizing or maximizing the dependent variable. Another problem that is potentially encountered when optimizing with multiple independent variables is nonsensical values returned by the software being used. For example, the optimization package 


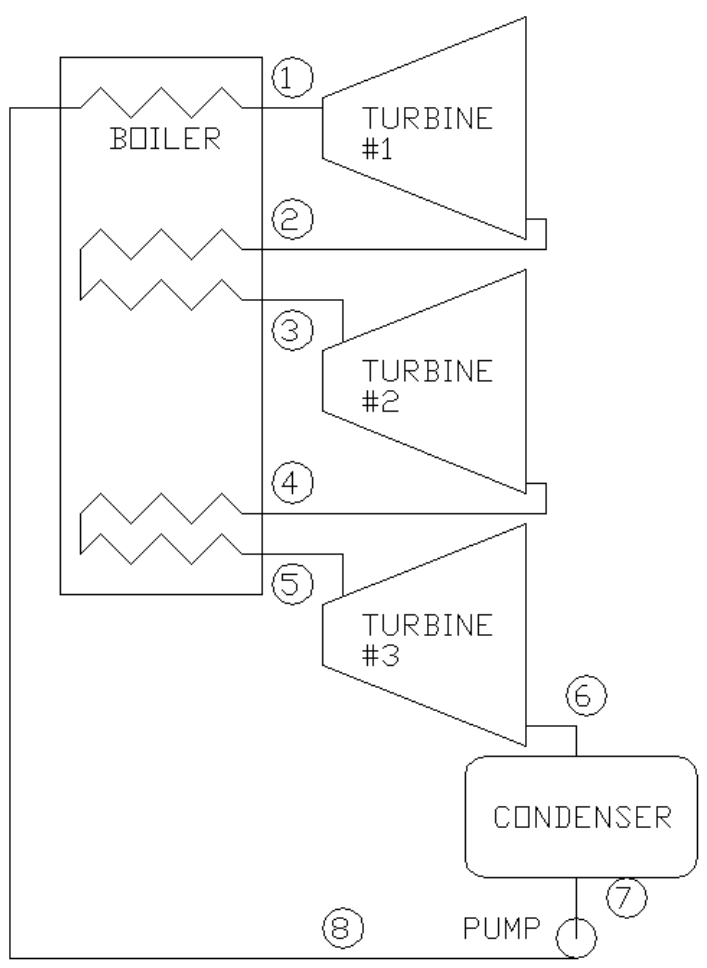

Figure 1. Plant schematic diagram with a double-reheat boiler and three turbines.

may not locate the true optimum efficiency and may return pressure values which are physically impossible, such as lower pressures than the condenser pressure or higher pressures than the boiler pressure. This can occur if the optimization package attempts to chase a local maximum as opposed to the true maximum efficiency. In such cases, constraints must be placed on the independent variables, which are the reheat pressures in this case, in order to find the true maximum efficiency.

The students normally find that the plant efficiency is somewhat insensitive to reheat pressures, at least as a first impression. Because of this, it is important in the early segments of the course to allow students to determine the annual revenue associated with an increase in plant efficiency of one tenth of a percentage point. Assuming a nominal $500 \mathrm{MW}$ plant with a thermal efficiency of 30 percent and a unit cost for electricity of 12 cents per $\mathrm{kWh}$, the annual gain in revenue associated with an increase in efficiency to 30.1 percent would be

$$
500 M W\left(\frac{365 \text { days }}{1 \text { year }}\right)\left(\frac{24 h r}{1 \text { day }}\right)\left(\frac{1000 k W}{1 M W}\right)\left(\frac{\$ 0.12}{k W h}\right)\left(\frac{0.1}{30}\right)=\$ 1,752,000 / y r
$$

The ratio $0.1 / 30$ represents the fractional change in plant efficiency that might come about, for example, by optimizing the reheat pressure values. The point to emphasize here is that the additional revenue shown above is a sizable amount of money which comes about through no additional operating expense on the part of the utility company, including labor, fuel, insurance or other recurring expenses. Therefore, any improvements that can be made in plant efficiency 
result in pure profit for the utility, which underscores the value of the plant design engineers and operating engineers in making the plant as efficient as possible. This can sometimes be accomplished in the physical powerplant by simply installing a throttle valve or a control valve to maintain a prescribed pressure.

\section{Homework Problem 2: Optimizing Feedwater Heater Pressures}

Normally one stage of feedwater heating is introduced during the sucussion of the Ranine cycle in a second course on thermodynamics. In such cases, an open feedwater heater is normally compared to a closed feedwater heater. In some cases, multiple feedwater heaters may be considered as shown in Figure 2. As with the homework problem addressing boiler reheat, the operating pressure for the feedwater heaters is normally given. With the use of computerized thermodynamic property functions, however, there is very little additional effort involved in optimizing the feedwater heater pressure values in order to maximize plant efficiency. Moreover, students are required to provide an initial pressure value for each stage of feedwater heating in order to facilitate the optimization process. In doing so, they notice the plant efficiency which resulted from their initially-chosen values prior to optimization and can compare that with the efficiency they obtain following optimization. Variations on this problem can be offered by introducing closed feedwater heaters as well as different condensate configurations, some of which involve pumping condensate forward and some of which may feature condensate that is drawn back to lower-pressure components in the plant without the need for a pump.

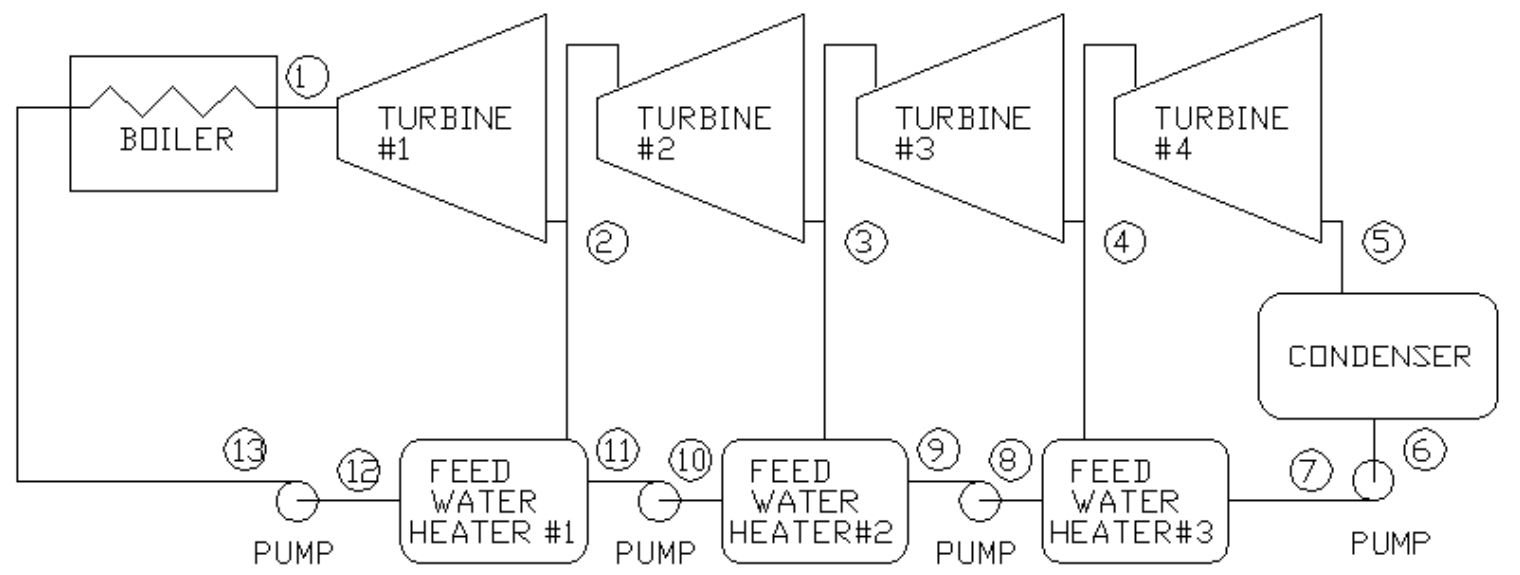

Figure 2. Plant schematic diagram with three feedwater heaters.

The efficiencies of these various configurations can be compared against each other, inspiring follow-on questions as part of the homework problems to discuss the reasons for any changes in efficiency observed. The concept of diminishing returns can be reinforced as the students add one, two, and three feedwater heaters and observe the reduced gain in efficiency with the addition of each component.

\section{Homework Problem 3: Cooling Tower Problems}

An important aspect of powerplant operation is heat rejection, whether this is the rejection of waste heat from the condenser or heat released from bearings and electrical generator heat. 
Cooling towers are commonly used for all of these various types of heat rejection. Properties need to be found for the moist air if the software being used does not compute this automatically. Humidity ratio can be calculated using standard methods like those found in Reference [11]

$$
\omega=\frac{0.622 P_{w}}{P_{a t m}-P_{w}}=\frac{0.622 \phi P_{\text {sat }}}{P_{a t m}-\phi P_{\text {sat }}}
$$

where $P_{w}$ is the partial pressure of the water vapor and $P_{a t m}$ is the overall atmospheric pressure. Also, $\phi$ is relative humidity and $P_{\text {sat }}$ is the saturation pressure of the water vapor for the local temperature. Specific volume can be found by

$$
v=\frac{R T}{P_{a t m}-\phi P_{\text {sat }}}
$$

The enthalpy of the mixture can then be calculated by

$$
h_{\text {mix }}=c_{p} T+\omega h_{\text {sat }}
$$

where $c_{p}$ is constant-pressure specific heat, $T$ is the temperature of the mixture in Celsius, and $h_{s a t}$ is the enthalpy of the saturated vapor for the local temperature. With these values obtained, an energy balance can be set up for the cooling tower and the desired unknown values can be solved for using Equation (5).

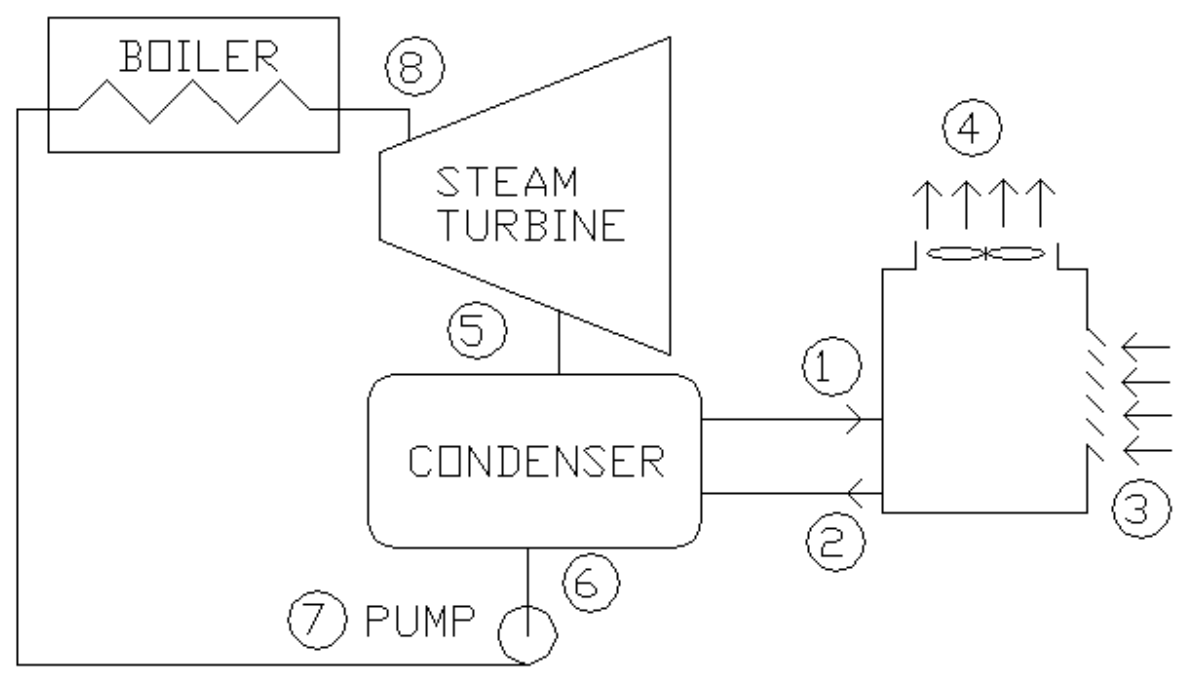

Figure 3. Schematic of integrated plant and cooling tower problem.

$$
\dot{m}_{w} h_{1}+\dot{m}_{a} h_{3}+\dot{m}_{m u} h_{m u}=\dot{m}_{w} h_{2}+\dot{m}_{a} h_{4}
$$


Examples of these might be $\dot{m}_{w}$ which is the cooling water flow rate, $\dot{m}_{a}$ which is the air flow rate, and $\dot{m}_{m u}$ which is the makeup water flow rate. Using the conservation of mass for water, the makeup water flow rate can also be found using

$$
\dot{m}_{m u}=\dot{m}_{a}\left(\omega_{4}-\omega_{3}\right)
$$

Finally, applying an energy balance to the entire system, the heat rejected from the condenser must equal the heat rejected from the cooling tower, so the following equations can be employed

$$
\dot{Q}=\dot{m}_{s t m}\left(h_{5}-h_{6}\right)=U A \Delta T_{l m}=\dot{m}_{a}\left(h_{3}-h_{4}\right)+\dot{m}_{m u} h_{m u}
$$

where $\dot{m}_{s t m}$ is the mass flow rate of the steam, $U$ is the heat transfer coefficient for the condenser, $A$ is the surface area of the condenser, and $\Delta T_{l m}$ is the log-mean temperature difference of the condenser. For convenience, and in order to make the equations solvable, the average temperature between $T_{1}$ and $T_{2}$ is given as being equal to $T_{4}$, which would naturally vary with the other temperatures. The objective of the exercise is to generate a graph of powerplant efficiency as a function of outdoor humidity for a given outdoor temperature. Since Equation (7) cannot be solved explicitly, each point on the plot must be found by establishing an initial value for condenser pressure and allowing the software to find the pressure which satisfies the equations. This homework problem allows students to employ the full range of thermodynamic principles they have used throughout the course and drives home the concept that weather conditions can have a significant impact on plant efficiency.

\section{Homework Problem 4: Gas Turbine Problem}

Gas turbines have become an increasingly significant component in electrical energy generation and are helpful in peak-shaving applications. Figure 4 shows a fairly simple gas turbine system with a regenerator. In this exercise, the students are asked to graph the efficiency of this system with respect to regenerator effectiveness from zero to 100 percent. The students find that, with an effectiveness of zero, the plant operates as if it had no regenerator. Next the students are asked to add in intercooler and recalculate the plant efficiency over the entire range of effectiveness values. Two intercoolers are then employed and the graph is repeated. The students ultimately submit three curves, all on the same set of axes, featuring plant efficiency as a function of regenerator effectiveness, with zero, one and two intercoolers.

\section{Homework Problem 5: Combined Cycle Pressure Optimization}

Similar to Homework Problem 4, this problem utilizes a gas turbine system wherein the turbine discharges to a boiler as opposed to a regenerator. The boiler provides steam for a Rankine cycle. The effectiveness of the boiler is given and the students are to optimize the pressure of the steam boiler in order to maximize overall plant efficiency. 


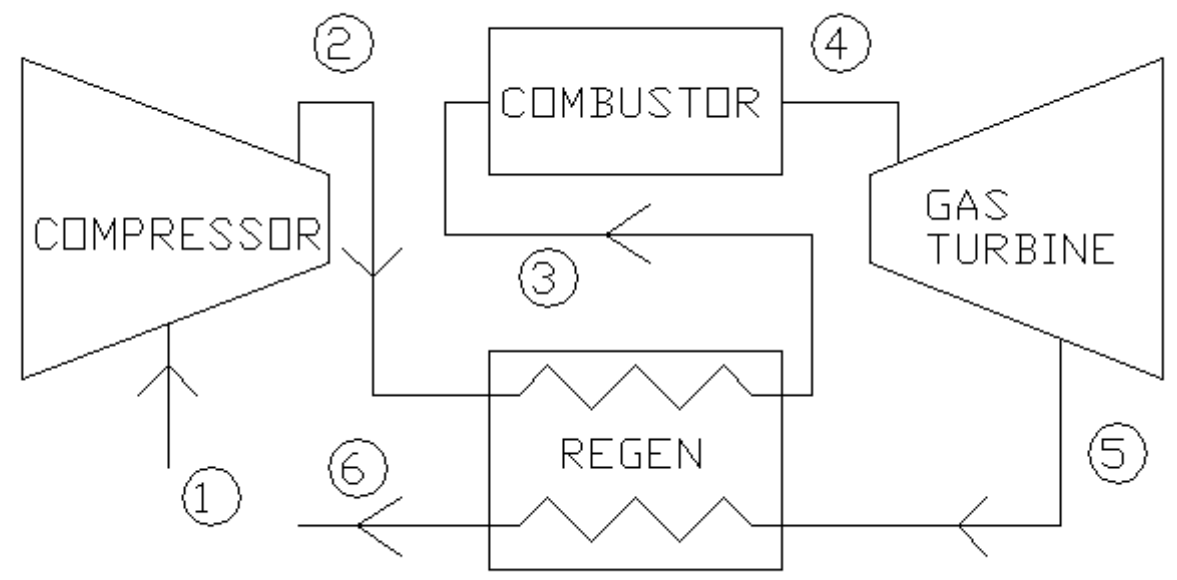

Figure 4. Gas turbine schematic diagram with a regenerator and no intercooling.

\section{Homework Problem 6: The Effects of Target Size on Neutron Thermalization}

Neutron thermalization is a crucial step in the neutron lifecycle related to the control of a reactor undergoing thermal fission. In most curricula, the fact that kinetic energy is lost most effectively in an elastic collision when the target is nominally the same size as projectile is simply conveyed to the students directly. This exercise is designed to convey that concept quantitatively by illustrating collisions with targets of three different sizes: one that is 100 times the mass of the projectile, one that is ten times the mass of the projectile, and one that is the same size as the projectile. Figure 5 shows the incoming particle of mass $m_{1}$ and the target particle, $m_{2}$ along with the angles associated with the directions of departure after impact, $\theta_{1}$ and $\theta_{2}$, with velocities $v_{1}$ and $v_{2}$, respectively.

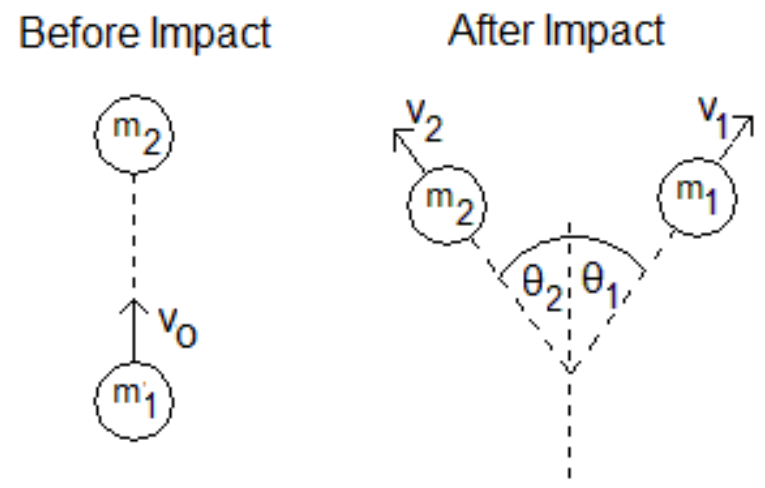

Figure 5. Collision between two elastic particles.

The target is assumed to be stationary prior to impact and the projectile has an initial velocity of $v_{\mathrm{o}}$. Three equations can be written from this figure, the first one utilizing conservation of momentum in the horizontal direction

$$
m_{1} v_{1} \sin \theta_{1}=m_{2} v_{2} \sin \theta_{2}
$$


the second one utilizing conservation of momentum in the vertical direction

$$
m_{1} v_{0}=m_{1} v_{1} \cos \theta_{1}+m_{2} v_{2} \cos \theta_{2}
$$

and the third one utilizing conservation of kinetic energy.

$$
m_{1} v_{o}^{2}=m_{1} v_{1}^{2}+m_{2} v_{2}^{2}
$$

These equations can be solved so that a value of $\theta_{2}$ can be found for each value of $\theta_{1}$ ranging from zero to 180 degrees. Figure 6 shows a plot of the fraction of energy lost in the collisions for each of the three cases. The plots show the significantly-greater energy loss from a collision of particles of approximately the same size, which points to the use of substances containing hydrogen as being the most effective moderators.

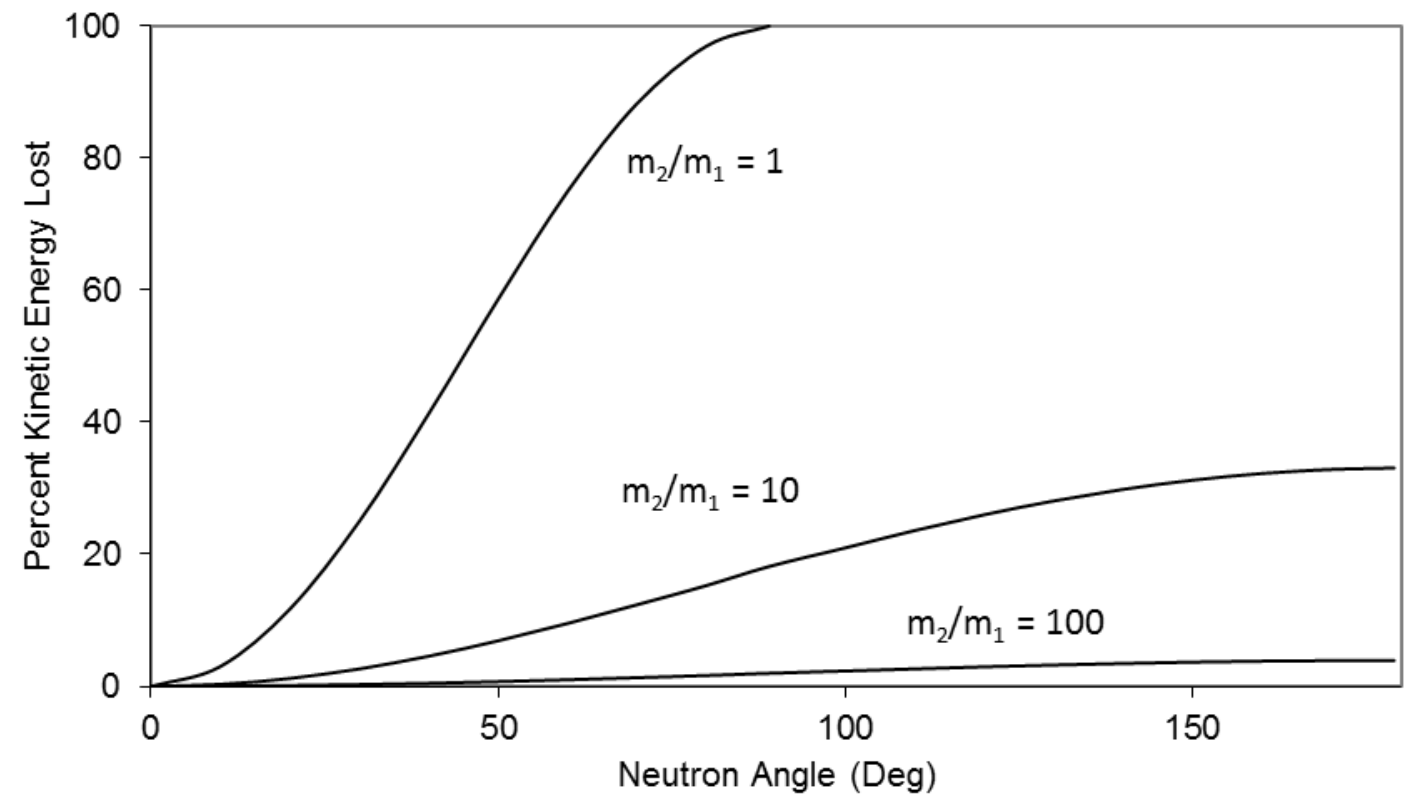

Figure 6. Loss of kinetic energy by a projectile when impacting targets of various relative masses over a range of angles.

\section{Homework Problem 7: Reactor Response to a Thermal Transient}

This problem started off by requiring students to compute the time required for water in a primary coolant loop to travel from the reactor pressure vessel to the steam generator and back again based on pipe sizes and lengths. They are told that the steam demand from the steam generator is being ramped up from $10 \%$ reactor power to $20 \%$ over a 10 -second period. Background information is provided regarding the reactivity associated with changes in temperature of the reactor moderator. A differential equation is derived in class showing the relationship between neutron flux level and reactivity changes due to changes in temperature 


$$
\frac{d \phi}{d t}=10 \alpha\left(T_{a v e}-T_{o}\right) \phi
$$

where $\phi$ is neutron flux level, which is directly proportional to reactor power, $\alpha$ is temperature coefficient of reactivity, $\mathrm{T}_{\mathrm{ave}}$ is the average temperature of the reactor, $\mathrm{T}_{\mathrm{o}}$ is the initial temperature of the reactor and the number 10 is an approximation for the reactor period in response to a change in reactivity. Students then discretize this equation using time steps of 0.2 seconds and account for the transit time associated with the primary coolant between the reactor pressure vessel and the steam generator. Figure 7 shows the resulting plot of the numerical solution for steam demand and the response of reactor power due to the changes in temperature initiated by the change in steam demand.

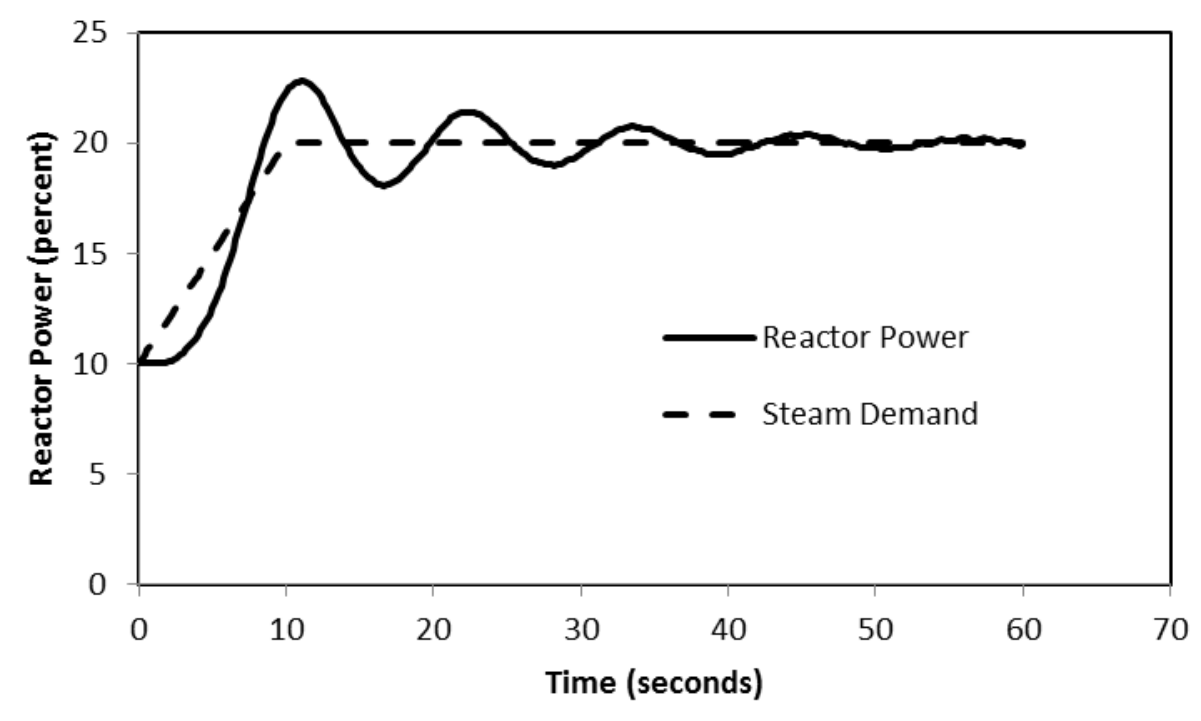

Figure 7. Reactor power in response to a change is steam demand.

\section{Assessment and Student Perceptions}

It is important to note that the students who normally enroll in the Powerplant Design course are normally the better students who tend to strive for perfection. They perform well on the homework exercises and homework averages were 9.35 out of 10 during the last semester in which the course was offered. With three hourly examinations and a three-hour final examination factored in, the fourteen students divided into three groups of final grades of 90100, 80-90, and 70-80 of 6, 7 and 1, respectively. Examinations were administered in a computer lab. Since the examination material was tailored to the types of problems given as homework assignments, it is difficult to determine how students would have done on examinations requiring thermodynamic properties to be interpolated. However, all 14 students enrolled in the course sat for, and passed, the Fundamental of Engineering examination during the same semester, which is a good indication of the ability of the students and their retention of classroom material. A student survey was administered and the results are shown in Table 1. Reactions were generally positive related to the use of computerized thermodynamic property 


\section{Table 1. Student survey regarding computerized thermodynamic properties}

(numbers in parentheses indicate the number of replies for each question)

1. What is your opinion about the use of computerized thermodynamic property retrieval in Powerplant Design class?

(5) I think it works extremely well and greatly enhances my understanding of powerplants.

(7) I think it works well and enhances my understanding of powerplants.

(1) I have no opinion either way.

(1) I sometimes wonder if it is worth the effort of learning the commands.

(0) I would rather interpolate properties from tables in a book.

2. What is your opinion about the use of homework problems assigned on the class web page?

(12) I greatly prefer working the problems on the web page as opposed to the textbook.

(1) I slightly prefer working the problems on the web page as opposed to the textbook.

(1) I have no opinion either way.

(0) I would slightly prefer working the problems in the textbook.

(0) I would greatly prefer working the problems in the textbook.

3. What is your opinion about the use of optimization in the homework problems (i.e. optimum re-heater pressure, feedwater heater pressure or intercooler pressure)?

(6) The optimization makes the problems much more realistic and interesting.

(7) The optimization makes the problems somewhat more realistic and interesting.

(1) I have no opinion either way.

(0) I would probably prefer not to learn about optimization in powerplant design.

(0) I think optimization detracts from the course.

4. When working computerized homework problems, I would prefer to use:

(7) The Excel format provided on the class web page.

(0) Thermodynamic properties in MATLAB.

(1) I have no preference either way.

(6) Engineering Equation Solver (EES).

(0) Thermodynamic properties in Mathcad.

5. Generating graphs in homework problems (i.e. efficiency as a function of outdoor humidity or regenerator effectiveness):

(9) gave me a good feel for how plant parameters affect overall plant performance.

(5) was somewhat interesting.

(0) did not seem to add to or detract from my understanding.

(0) was not helpful.

(0) detracted from my understanding of the homework assignments. 
retrieval and system optimization in the course. Replies were overwhelmingly positive regarding the web-based nature of the homework assignments. The students were nearly evenly split on whether they preferred EES as a means of determining thermodynamic properties or the Excelbased thermodynamic property program in Reference [8]. The classroom examples were all demonstrated using Excel and the primary reason for the preference for EES is the automatic unit conversion feature, eliminating the need to convert units manually, which is required when using Excel.

\section{Summary}

Although the number of mechanical engineering departments offering a course in powerplant design may be small, the inclusion of powerplant design concepts is important in intermediate or advanced thermodynamics courses. Computerized thermodynamic property retrieval is important in such courses, since the work involved with interpolation from tables is not beneficial to the students. The homework exercises provided here have been well-received by students and allow them to see the integrated effects of the components of a plant to its overall performance. Even aspects of nuclear power are introduced using student-written computer solutions to generate numerical results as opposed to rote learning from a textbook or from a slide presentation in class. The calculation aspect of presenting the material in this way holds student interest and gives them a more foundational understanding of the physical effects of varying system parameters.

\section{References}

[1] S. McClain, "MathCAD Functions for Thermodynamic Analysis of Ideal Gases," Proceedings of the 2005 ASEE Conference, Portland, Ore., June 2005.

[2] S. McClain, "A Mathcad Functions Set for Solving Thermodynamic Problems", Proceedings of the 2006 ASEE Conference, Chicago, 2006.

[3] M. Maixner, J. Christopher, V. Sharma, and A. Parks, "Power Plant Analysis With Mathcad", Proceedings of the 2008 ASEE Conference, Pittsburgh, Pa, June 2008.

[4] M. Maixner, "Interactive Graphic Depiction of Working Fluid Thermal Properties Using Spreadsheets", Proceedings of the 2006 ASEE Conference, Chicago, Ill., June 2006.

[5] M. Maixner, "Excel Analysis of Combined Cycle Power Plant", Proceedings of the 2005 ASEE Conference, Portland, Ore., June 2005.

[6] SpreadsheetWorld, "Offering Spreadsheet Aided Engineering Courses Since 1995," spreadsheetworld.com, accessed 26 Dec 2015.

[7] R. Taylor, J. Chappell, and K. Woodbury, "Introducing Excel-Based Steam Table Calculations into Thermodynamics Curriculum," Proceedings of the 2008 ASEE Conference, Pittsburgh, Pa, June 2008. 
[8] M. Holmgren, "Steam Tables by Magnus Holmgren," ascentengineering.com/Documents/XSteam_Excel_v2.6_US.xls, accessed 22 Dec 2015.

[9] S. Dechant, C. Damm, B. Egan, "Building as a Power Plant: Modeling and Selection of a Combined Heat and Power System for an Advanced Commercial Building," Proceedings of the 2007 ASEE Conference, Honolulu, Hi., June 2007.

[10] M. El-Wakil, Powerplant Technology, McGraw Hill, 1984.

[11] Y. Cengel and M. Boles, Thermodynamics, an Engineering Approach, Sixth Edition, McGraw Hill, 2007. 